\title{
Poems
}

Joe Montenegro Bonilla

\section{People Happen}

$\mathrm{P}$ eople happen everyday. They conquer distance

L and travel from faraway citadels just to happen in other people's streets.

They happen suddenly, and laconically, but they happen trulyreceive a close celestial call to step into the light of other people's lamps.

And people also happen at my placenot every morning, not every night, yet with a certain regularity.

They happen when they want, not upon my call.

Something or someone there is that bids them happen, to show up at my door, to never ring the bell.

Some I drive off, Some I usher in, happy they happened.

One way or the other, people happen constantly and enter me.

Still, you happen not.

\section{Upon a Small Accident}

$\tau$

heard of You today, Before, during, and after.

My tight shut eyes saw You. My tight closed grip grabbed You.

Skidding wheels upon the road, Devil's ballerinas darkly flowed Through an asphyxiating cloud That clogged my sight upon the ground.

But I'm harnessed to You, Buckled up so close to You.

And there was movement in the airSome say fluttering; I say prayer-, And through the cloud of mud and fear, I heard of You that You were near. 


\section{From Here}

1 way from the wooden twelvepaned door,

Beyond the clinking bars of the fence,

With that door and those bars stuck in my nostrils.

Away caring much and carrying much. Caring much about the old and new rafters

Because the rafters have uttered their oath

- a bobbing torch in my hand.

Away, led by my own threshold and lintel,

But not just through the window this time

- a quick ride on board of my front porch rug.

Away in an unfamiliar way,

Por un momento,

Just for a cold breath, but back in right away.

Away, out and back in for a new tap on the floor;

Away wearing every tile,

Wearing oil hues and varnish makeup.

Away but not too far away;

Sent with a pair of clean shoes

Into the enlivening mud.

Away to come back and paint footprints on the floor.

Away for some perspective, For some architecture.

Away until I find my way.

\section{Reply}

2 ut what if there's a place like that?

What if there's a land where life flows, springs up, and showers the rocks-

all at once-?

What if there's a place where bewitching streams

wash fear and confinement away?

What if there's a country where the entrails of the earth

roar with a scarlet zest?

I mean-

What if you can find golden beads down there?

What if you find a narrow log to keep the feeble fire alive?

Were there a place like that,

Wouldn't you move there for good?

\section{This Is How I Get It}

In memoriam $M$. $G$.

bout her, anything may be
said-
that she's slow at understanding or, because cynical, an ungrateful bugbut never, never that she's false.

Let it never be said that Death is false.

She may be naïve and even stupid, or on the contrary, vast in intellect and complexity-

sophisticated even, too proud maybe, or else dull and tasteless,

yet never false. 
She apologizes not-

that's common knowledge-

why should she

who never lies?

That's what Death is like.

That's what yours was like-

not insipid or vane,

neither eternal nor circumstantial-

unnecessary perhaps-for me-

maybe alien and never vague,

yet always truthful.

Your death spoke

with a warm and lessening voice,

far more than the truth of your pres-

ence.

In her phonemes there's still passion, clear like the shadows

of the dawn,

but strident like the neighboring clam-

or

that comes through my window.

She spoke of you;

she spoke of me.

She spoke of the scenes that were found in the bottom of my tears, though the sea was saltier and the sand not so rough.

Your death is mine to grasp, to smell and chew on, to uncover completely and look inside and find in her the words, the most truthful and plainest that time has ever uttered.

Your death is lifethat's common knowledge-, for she leads me to days uncounted, to truths surmounted. 
